\title{
A Systematic Literature Review of Empirical Studies on Learning Analytics in Educational Games
}

Ahmed Tlili ${ }^{1}$, Maiga Chang ${ }^{2,7}$, Jewoong Moon ${ }^{3}$, Zhichun Liu ${ }^{4}$, Daniel Burgos ${ }^{5 *}$, Nian-Shing Chen $^{6}$, Kinshuk ${ }^{8}$

${ }^{1}$ Smart Learning Institute of Beijing Normal University, Beijing (China)

${ }^{2}$ School of Computing and Information Systems, Athabasca University, Edmonton (Canada)

${ }^{3}$ Florida State University, Tallahassee (USA)

${ }^{4}$ University of Massachusetts Dartmouth, Dartmouth (USA)

${ }^{5}$ Research Institute for Innovation \& Technology in Education (UNIR iTED), Universidad Internacional de La Rioja (UNIR), 26006, Logroño, La Rioja (Spain)

${ }^{6}$ Department of Applied Foreign Languages, National Yunlin University of Science and Technology, 123 University Road, Section 3, Douliou, Yunlin (Taiwan)

${ }^{7}$ Department of M-Commerce and Multimedia Applications, Asia University, 500 Liufeng Road, Taichung City, 41354 (Taiwan)

${ }^{8}$ University of North Texas, 3940 N. Elm Street, G 150, Denton, TX, 76207 (USA)

Received 12 October 2020 | Accepted 13 February 2021 | Published 12 March 2021

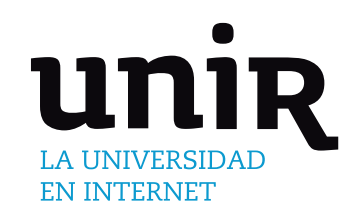

KEYWORDS

ABSTRACT

Learning analytics (LA) in educational games is considered an emerging practice due to its potential of enhancing the learning process. Growing research on formative assessment has shed light on the ways in which students' meaningful and in-situ learning experiences can be supported through educational games. To understand learners' playful experiences during gameplay, researchers have applied LA, which focuses on understanding students' in-game behaviour trajectories and personal learning needs during play. However, there is a lack of studies exploring how further research on LA in educational games can be conducted. Only a few analyses have discussed how LA has been designed, integrated, and implemented in educational games. Accordingly, this systematic literature review examined how LA in educational games has evolved. The study findings suggest that: (1) there is an increasing need to consider factors such as student modelling, iterative game design and personalisation when designing and implementing LA through educational games; and (2) the use of LA creates several challenges from technical, data management and ethical perspectives. In addition to outlining these findings, this article offers important notes for practitioners, and discusses the implications of the study's results.

\author{
Learning Analytics, \\ Educational Data \\ Mining, Educational \\ Games, Systematic \\ Literature Review.
}

DOI: $10.9781 /$ ijimai.2021.03.003

\section{IntRODUCTION}

$\mathrm{E}$ DUCATIONAL games are immersive, interactive and can engage students in dynamic learning-and-playing processes. They have therefore been used in various disciplines, such as computer architecture [1], mathematics [2], language learning [3][4] and science [5], as well as in online contexts [6][7]. Unlike in traditional learning management systems, users generate massive data while interacting with educational games. Therefore, collecting and synthesising students' en-route behaviour patterns, intellectual states and emotional level in gameplay become essential to identifying how their playful learning occurs. Researchers have sought various ways to utilise this data to identify how to accurately observe students' learning process through learning analytics (LA) [8]. LA refers to the collection and analysis of learners' intellectual and behavioural attributes to optimise learning experiences [9]. Several studies on educational games have

${ }^{*}$ Corresponding author.

E-mail address: daniel.burgos@unir.net also focused on adopting unobtrusive ways to use LA approaches to measure students' progressions without interrupting the flow of their gameplay [10] [11]. In particular, using stealth assessment in educational games has broadened the role of real-time and automatic assessments in educational games [12]. Moving away from existing approaches that rely on external measures (e.g. post-test), recent research has sought ways to promptly measure how students' in-situ learning occurs while they are experiencing ongoing gameplay.

The LA field has expanded in recent years because it allows educators to perform formative assessments that accompany fine-grained and contextual feedback tailored to the various needs of individuals in learning environments. For instance, recent implementations of educational games have integrated formative assessments with LA [13] [14]. Serving as a mechanism of such assessment, LA in educational games aims to identify and interpret students' meaningful progressions or task challenges in gameplay. Subsequently, game elements and supports (e.g. feedback, learning sequence and presentation of materials) are tailored to individual needs (e.g. domain knowledge, cognitive competence, or affective states). 
Despite the emerging significance of LA when implementing educational games, a limitation also remains. There is a lack of comprehensive guidelines for LA design, development, and implementation, because analytic approaches are game- and contextspecific, resulting in high variations in adoption. Specifically, this issue limits developers' ability to define general analytics to effectively incorporate LA in educational games [15]. In other words, the applications of LA in educational games still appear complex, and generally acceptable approaches have rarely been reported [16]. This fact implies that it is necessary to perform a comprehensive review to explore how LA has been integrated and implemented in educational games.

Accordingly, this study conducts a systematic literature review to better understand the potential implementations of educational games across various contexts. The goal of this study is to advance this field by (1) exploring why and how LA has been implemented across various learning contexts and (2) discussing existing limitations and challenges in integrating LA in educational games. This study is structured as follows: Section II presents the background of LA in educational games and highlights the research gap this study aims to address. Section III presents the research method followed to conduct the systematic literature review. Section IV presents the findings of this study, while section V discusses these findings. Finally, section VI concludes the study with general notes and future directions.

\section{BACKGROUND OF LA in EdUCATIONAL GAMES}

LA is an interdisciplinary field associated with many domains, including data science, artificial intelligence, practices of recommender systems, and online marketing and business intelligence [17]. LA is defined as 'the measurement, collection, analysis and reporting of data about learners and their context, for purposes of understanding and optimising learning and the environments in which it occurs' [18]. Powell and MacNeill [19] highlighted key applications of LA, namely to: (1) offer feedback for students about their learning performance; (2) predict at-risk students who may fail to pass their final exams; (3) help educators to provide interventions when needed; (4) improve the design of courses; and (5) support decision-making when it comes to administrative tasks. LA has been increasingly prominent because it enables researchers to collect, interpret and share meaningful data that inform how learners interact with a learning environment.

The applications of LA are rooted in the usage of formative assessment in learning. A formative assessment is one that is integrated into the learning experience without interruptions during students' gameplay [11]. Research suggests the importance of formative assessments in informing educators about which cognitive and emotional challenges students may experience. In addition, formative assessment can prompt educators to decide on the types of adaptive learning supports (in-game help and game tasks) to use to foster students' deep learning [12]. Specifically, a current stream of a stealth assessment has explored feasible implementations of formative assessment in educational games [21][22]. Since educational games yield highly interactive and massive traces of learners' in-game behaviours, researchers have considered the latent uses of LA in educational games. In the same vein, Alonso-Fernandez, Calvo, Freire, Martinez-Ortiz and Fernandez-Manjon [23], as well as Tlili and Chang [24], have stated that educational games without analytics are like black boxes that barely offer meaningful clues to students' learning process during their play.

Hence, LA is applied in educational games to better capture how students' improvement and challenges occur without interrupting their flow, and then to inform tailored feedback for game-based learning experiences. However, previous studies rarely suggested how and why LA techniques are capable of supporting learners' play in educational games. This gap demonstrates that it is essential to understand (1) what are the objectives of implementing LA in educational games; (2) what are the educational game contexts; and (3) how such factors (objectives and game contexts) can influence various LA implementations in educational games.

Despite the potential of future combinations of LA and educational games, integrating those two systems remains challenging. Papamitsiou and Economides [25] asserted that further explorations using LA in educational games are necessary because understandings of the intersection between LA and interactive learning environments are still vague. Saveski et al. [26] revealed that 21 European game studies demonstrated a high interest in applying LA in educational games, but the researchers were concerned with the complexity of implementation. Like previous researchers, Perez-Colado, PerezColado, Freire-Moran, Martinez-Ortiz and Fernandez-Manjon [16] mentioned that the application of LA in educational games is still a complicated process, despite the fact that there are several platforms which combine both educational games and analytics. Therefore, given the gap between the advancement of LA technologies and their practical implementations in educational games, a further systematic literature review is necessary to gain insights that can close the gap. To address the questions above, we proposed four primary research questions in this study.

- RQ1. What are the objectives of applying LA in educational games?

- RQ2. What genres of educational games have applied LA, and what types of game metrics were used in the application of LA?

- RQ3. What types of LA approaches were used in educational games?

- RQ4. What are the challenges in applying LA in educational games?

\section{METHOD}

A systematic literature review of empirical studies using LA in educational games was conducted based on the major steps outlined by Okoli and Schabram [27].

\section{A. Data Collection and Search Criteria}

Several keywords, including 'learning analytics AND educational games', 'learning analytics AND game-based learning' and 'educational data mining in games' were used in searches in different electronic databases, namely Taylor \& Francis Online, IEEE Xplore Digital Library, ScienceDirect, AIS Electronic Library, Springer, Wiley Online Library, ACM Digital Library, ProQuest and Semantic scholar. As shown in Fig. 1, these searches yielded a total of 405 studies conducted from 2012 to 2019 . Of those, 180 studies were removed since they were found to be duplicated. The remaining 225 studies were then evaluated by title, abstract and, if necessary, by full text, based on the inclusion and exclusion criteria described in Table I. In the end, only 36 studies met the inclusion criteria, and those studies were double-checked again through readings of the full text.

TABLE I. INCLUSION AND EXCLUSION CRITERIA

\section{Inclusion and Exclusion Criteria technique}

Articles that are published in peer-reviewed journals.

Articles that are empirical studies and report rigorous study procedures and their findings.

Articles that involve human subjects.

Articles that have their full text available online.

Articles that apply LA in educational games. 


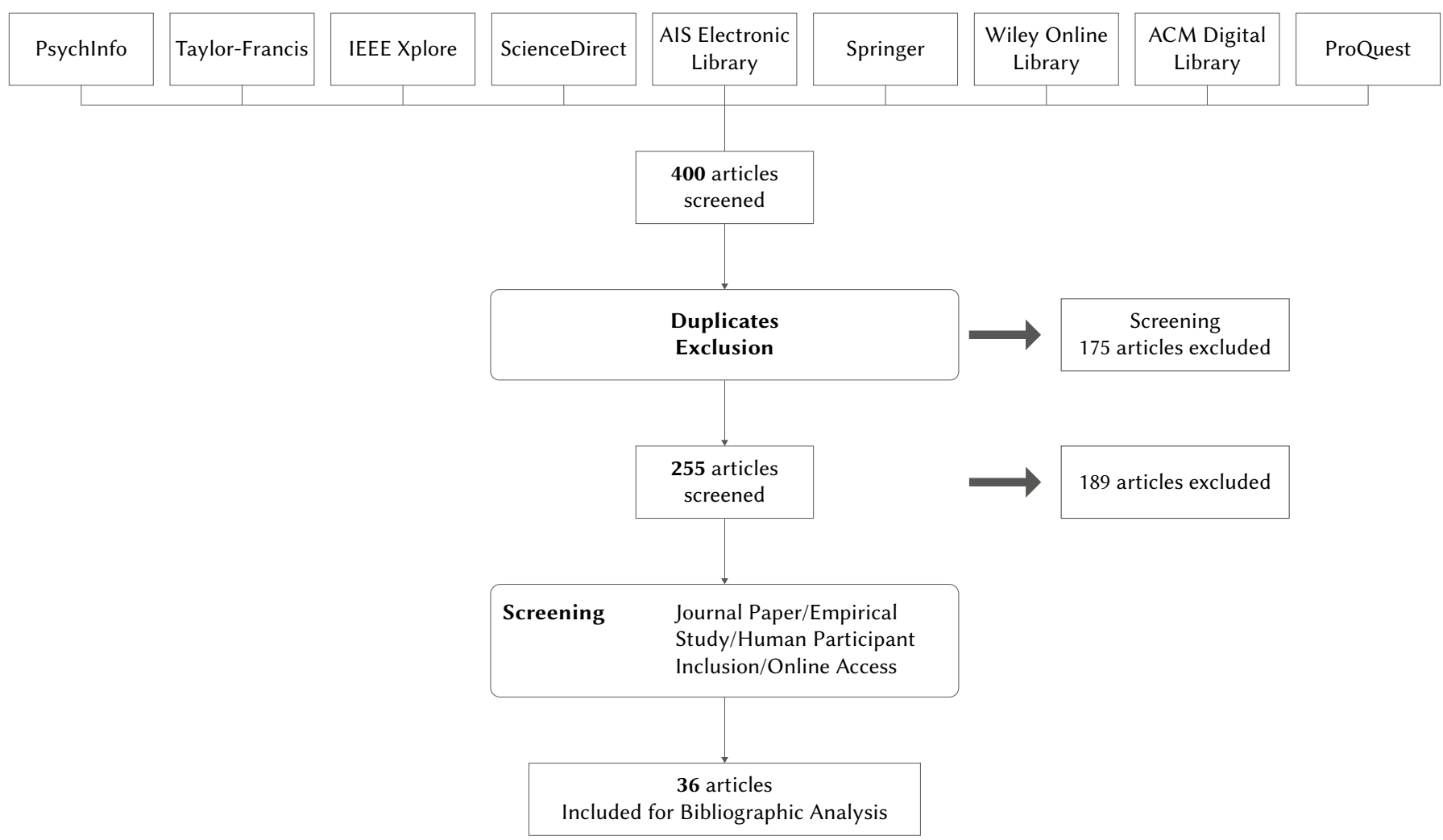

Fig. 1. Flowchart of the systematic review process.

\section{B. Coding Procedure}

Each study in the literature was coded for different characteristics. As this study aimed to explore LA designs and implementations in educational games, we took into consideration existing integrations of LA in combination with major features of educational games discussed in the sampled studies. Hence, two major coding schemes presented in two systematic literature reviews guided our coding scheme in this study, namely Papamitsiou and Economides [25] for LA and Connolly et al. [28] for educational games. In addition to the basic article information (e.g. year of the study, journal name), we evaluated the LA objective and technical information (i.e. LA approach, whether the LA was embedded in the game or not and LA challenges). In addition, we evaluated environmental information (i.e. game genre and game mode) and the metrics of the educational games highlighted in these studies. Table II presents the detailed coding scheme of this study. Finally, suggested by Webster and Watson [29], the coding results were then organized in a table (see Appendix I), which formed the abstract of this systematic literature review.

We designed an initial coding protocol for multiple coders who are experts on educational games and LA. Based on the coding scheme presented in Table II, we carried out training using a subset of the literature for this study. The coder training was conducted until all coders reached consensus. When individuals' coding results differed, all coders iteratively discussed their results to reach an agreement. A detailed summary of the articles reviewed based on the coding variables is presented in Appendix I.
TABLE II. Coding of Reviewed Research Papers Examining LA in Educational Games

\begin{tabular}{|c|c|c|}
\hline Variables & Description & Coding Criteria \\
\hline Year & $\begin{array}{l}\text { Year study was } \\
\text { conducted }\end{array}$ & Year \\
\hline $\begin{array}{l}\text { LA } \\
\text { objective }\end{array}$ & $\begin{array}{l}\text { Goal of applying LA } \\
\text { in educational games }\end{array}$ & $\begin{array}{l}\text { - Understanding and modelling } \\
\text { students' in-game behaviours } \\
\text { - Formative design of educational } \\
\text { games } \\
\text { - Implementing teaching supports } \\
\text { - Conducting learning assessments } \\
\text { - In-game personalisation }\end{array}$ \\
\hline $\begin{array}{l}\text { LA } \\
\text { approach }\end{array}$ & $\begin{array}{l}\text { The approach used to } \\
\text { analyse data }\end{array}$ & $\begin{array}{l}\text { - Data mining and analytics (e.g. } \\
\text { lag-sequential analysis and social } \\
\text { network analysis) } \\
\text { - Data visualization } \\
\text { - Sequential data analytics }\end{array}$ \\
\hline Challenge & $\begin{array}{l}\text { The challenges of } \\
\text { LA application in } \\
\text { educational games }\end{array}$ & $\begin{array}{l}\text { Report the mentioned challenges } \\
\text { during the application of LA in } \\
\text { educational games }\end{array}$ \\
\hline $\begin{array}{l}\text { Embedded } \\
\text { analytics }\end{array}$ & $\begin{array}{l}\text { Was the LA procedure } \\
\text { incorporated within } \\
\text { the educational game? }\end{array}$ & Yes / No \\
\hline $\begin{array}{l}\text { Game } \\
\text { mode }\end{array}$ & $\begin{array}{l}\text { The mode of the } \\
\text { educational game used } \\
\text { while applying LA }\end{array}$ & $\begin{array}{l}\text { Single player / multi-player / } \\
\text { massively multiplayer }\end{array}$ \\
\hline $\begin{array}{l}\text { Game } \\
\text { metrics }\end{array}$ & $\begin{array}{l}\text { The metrics used } \\
\text { within educational } \\
\text { game for LA }\end{array}$ & $\begin{array}{l}\text { Report the actual collected traces } \\
\text { for LA }\end{array}$ \\
\hline
\end{tabular}




\section{FINDINGS}

\section{A. RQ1. What Are the Objectives of Applying LA in Educational} Games?

This section found major objectives of LA in educational games: understanding and modelling students' in-game behaviours (13 studies); creating formative designs for educational games (7 studies); implementing teaching support (8 studies); conducting learning assessments (13 studies); personalising in-game features (2 studies). It should be noted that several studies applied LA in educational games for more than one purpose [30]. Each key application is described in the subsequent sections. Appendix I includes the details of coded articles for this study.

\section{Understanding and Modelling Students' In-game Behaviours}

A group of studies has examined students' in-game behaviours [31] [32] [33] [34] [35] [36] [37] [38] [39] [40] [41] [42] [43] to identify gameplay patterns. Using collected data about such behaviours, researchers aimed at understanding students' behaviour patterns and their inherited characteristics during gameplay. For example:

- [40] Liu et al. used LA to implement in-game behaviour log analysis to collect students' time- and date-stamped actions. They implemented data visualisations of collected student log data to represent students' pattern of use of in-game tools (e.g. database, notebook, and probes).

- [42] Martin et al. used LA to explore how groups of students solved in-game tasks related to fractions. Using hierarchical clustering, this study identified three gameplay patterns.

Furthermore, researchers also observed students' in-game behaviours to obtain evidence of modelling that reflected either affective or cognitive states attained during gameplay.

- Affective state: Denden et al [33] and Essalmi et al [34] modelled the students' personalities, specifically extraversion and openness dimensions, based on their gaming behaviours and LA $[9,10]$.

- Cognitive state: Khenissi et al. [39] implemented LA in a memory match game to implicitly model the students' working memory capacity using a fuzzy logic algorithm.

\section{Formative Design of Educational Games}

Using LA was also beneficial in carrying out formative designs of educational games [15] [44] [45] [46] [47] [48] [49]. Specifically, LA enabled game designers and educators to understand how educational games can be better designed through assessments of students' play logs and observed behaviour. As examples of such design studies on educational games:

- [15] Serrano-Laguna, Torrente, Moreno-Ger and FernándezManjón carried out data visualisations to detect cases of outlier behaviour from students. Using collected data, they identified the types of learner challenges that appeared during gameplay.

- [49] Chaudy and Connolly used the LA engine EngAGe integrated with an educational game. This engine is designed to allow both game developers and educators to conduct iterative designs of an assessment that is capable of in-game adaptions to players.

\section{Implementing Teaching Supports}

LA played a role in the development of teaching supports to foster students' learning in educational games [30] [45] [46] [50] [51] [52] [53] [54]. First, researchers used LA to provide students' records of learning profiles in a game system. The use of teaching supports was found to enhance students' attention and then help them cope with challenges during gameplay. Some studies included examples of how teaching supports were applied and implemented across different domains.
- Providing a visual dashboard demonstrating real-time behaviour data

- [30] Minović, Milovanović, Šošević and González incorporated an analytical tool in an educational game that generated a realtime dashboard (e.g. using circular graphs) for teachers to use when teaching computer networks. They used this dashboard to keep track of their students' trajectories and support their learning when needed.

- [51] Chen and Lee applied LA to help students learn English vocabulary in an educational game. The game in this study tracked students' answers to inform teachers of students' learning states, providing warning messages and suggestions to enhance the learning process.

- Providing learner profile data for teachers' decision-making

- [54] Rodríguez-Cerezo, Sarasa-Cabezuelo, Gómez-Albarrán and Sierra created an analytics tool in generated educational games for teaching computer language implementation to help teachers control their students while learning occurred and to assess their performance.

\section{Conducting Learning Assessments}

LA in educational games served as learning assessments. The key to assessment in educational games was to unobtrusively measure students' learning progressions across various subjects. A collection of studies implemented LA to identify learners' progression in in-game performance, problem-solving skills or knowledge acquisition [11] [15] [30] [52] [55] [56] [57] [58] [59] [60] [61] [62] [63].

- In-game performance [58][59][60]: a group of researchers used LA in an educational game to model students' knowledge levels, in order to allow researchers to compare expert and novice scores. Such studies used similarity indices that represented to what extent students' in-game performance emerged.

- Problem-solving [56]: Hernández-Lara, Perera-Lluna and Serradell-López applied LA in a simulation game that taught students decision-making and management skills. They aimed to implicitly observe students' interaction behaviours in relation to target learning outcomes.

- Knowledge [61]: Rowe et al. considered LA approaches in two developed educational games (Impulse and Quantum Spectre). Using game log data, this study detected learners' strategic behaviours concerning various scientific concepts (e.g. Newtonian physics).

\section{In-game Personalisation}

Research has implemented personalisation to automatically provide students with adaptive learning experiences in educational games [11] [53]. Adaptivity in educational games refers to providing appropriate level of challenge and tailored feedback in an educational game [5]. In accordance with this rationale, some studies have adjusted game designs to reflect learners' needs and challenges.

- [11] Reese, Tabachnick and Kosko adopted their actionable measurement system to indicate learners' progress on their ingame performance. In their educational game CyGaMEs, the game system provided students with embedded learning support and a performance progression bar showing personalised data visualisations that indicated how close students were to meeting their in-game goals.

- [53] Kiili, Moeller and Ninaus applied LA in an educational game for teaching fractions and decimals to provide personalised hints based on each student's misconceptions. 
B. RQ2. What Genres of Educational Games Have Applied LA, and What Types of Game Metrics Were Used in the Application of LA?

As Fig. 2(a) shows, the educational game genres in which LA is most often applied are role-playing games (11 studies) and puzzle games (9 studies). This finding suggests that research tend to use roleplaying games because those games enable students to experience playful learning in correspondence to a given narrative in a virtual environment. Moreover, role-playing games provide a media-rich environment, including interactions, activities, and places; hence, behaviour traces can be generated, tracked and used in LA everywhere in such a game environment. Puzzle games have also been used extensively, primarily because they can facilitate students' problemsolving and reasoning [64] [65]. On the other hand, as Fig. 2(b) shows, the most used educational game type in which LA is applied is the single-player game (31 studies out of 33). This result suggests that previous games were designed to promote individuals' self-regulated actions in individual adventures.

Prior studies have used several types of in-game metrics across different game genres. Such games have applied LA to meet different

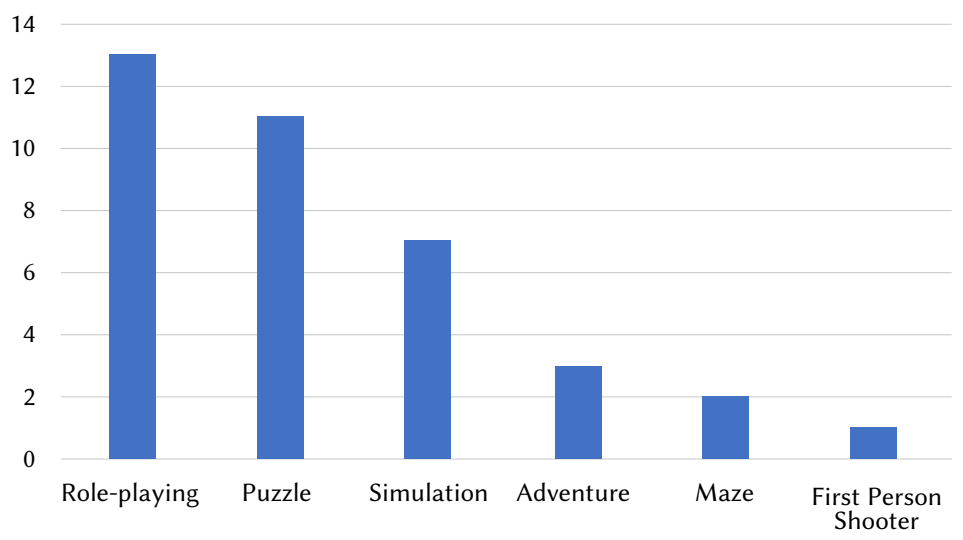

(a)

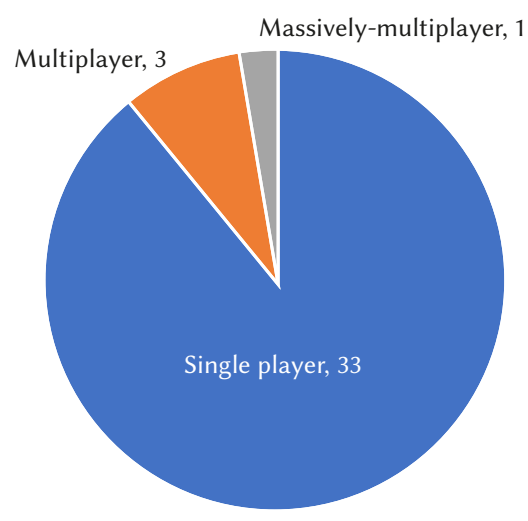

(b)

Fig. 2. Used game genres and types for la ( $a=$ game genres, $b=$ game types).

TABLE III. Coding of Reviewed Research Papers Examining LA in Educational Games

\begin{tabular}{|c|c|c|c|}
\hline Target measures & $\begin{array}{l}\text { Type of game } \\
\text { metrics }\end{array}$ & Examples & Description \\
\hline \multirow[t]{2}{*}{$\begin{array}{l}\text { Performance } \\
\text { measure }\end{array}$} & $\begin{array}{l}\text { In-game } \\
\text { performance }\end{array}$ & $\begin{array}{l}\text { - Game score } \\
\text { - Reached game level } \\
\text { - Number of correct/wrong answers }\end{array}$ & $\begin{array}{l}\text { In-game performance measures can keep track of students' in-game } \\
\text { performance in relation to learning. }\end{array}$ \\
\hline & Time on task & $\begin{array}{l}\text { - Time spent in each scene } \\
\text { - Interaction time } \\
\text { - Time solving a level }\end{array}$ & $\begin{array}{l}\text { Researchers focused on measuring the time duration by either students' } \\
\text { performance in the game in general or in a particular in-game activity or } \\
\text { quest. This metric was specifically used to measure either how much time } \\
\text { they paid attention to gameplay or how they efficiently accomplish game } \\
\text { tasks. }\end{array}$ \\
\hline \multirow[t]{4}{*}{$\begin{array}{l}\text { Behavioural } \\
\text { measures }\end{array}$} & Game interaction & $\begin{array}{l}\text { - Used game characters } \\
\text { - Interacting with game tools/ } \\
\text { elements } \\
\text { - Number of clicks }\end{array}$ & $\begin{array}{l}\text { In terms of interaction with the game tools/elements, research focused on } \\
\text { using the interaction of students with different game elements (found in } \\
\text { the game environment) or game tools (provided by the game as tools to } \\
\text { further support the learning process). The purpose of game interaction is } \\
\text { to capture all the interactions of players. }\end{array}$ \\
\hline & Learning behaviour & $\begin{array}{l}\text { - Number of times using the help } \\
\text { - Note-taking }\end{array}$ & $\begin{array}{l}\text { Learning behaviours refer to the specific game interactions that are } \\
\text { identified to be related to learning. The purpose of learning behaviour is } \\
\text { only to capture the meaningful interactions of players. }\end{array}$ \\
\hline & Progression & $\begin{array}{l}\text { - Game location } \\
\text { - Followed path } \\
\text { - Progress in the game }\end{array}$ & $\begin{array}{l}\text { These metrics focus on tracking the students' game trajectories or paths } \\
\text { while learning in the game environment. }\end{array}$ \\
\hline & Timestamp & & $\begin{array}{l}\text { Timestamping usually works with the game interactions, learning } \\
\text { behaviours and progression to mark the chronological sequence of } \\
\text { gameplay. }\end{array}$ \\
\hline \multirow[t]{2}{*}{$\begin{array}{l}\text { Multi-faceted } \\
\text { measure }\end{array}$} & Discourse & $\begin{array}{l}\text { - Dialogue } \\
\text { - Verbal communication }\end{array}$ & $\begin{array}{l}\text { Researchers focused on collecting chat/forum communications among } \\
\text { students generated while those students were playing an educational game. }\end{array}$ \\
\hline & Player information & $\begin{array}{l}\text { - Personal information } \\
\text { - Student name and age }\end{array}$ & $\begin{array}{l}\text { These metrics are out of the game but can provide background information } \\
\text { on players. }\end{array}$ \\
\hline Challenge & Physical behaviour & Gesture & $\begin{array}{l}\text { This type of metric looks beyond in-game performance. Bioinformation } \\
\text { can be tracked similarly. }\end{array}$ \\
\hline
\end{tabular}




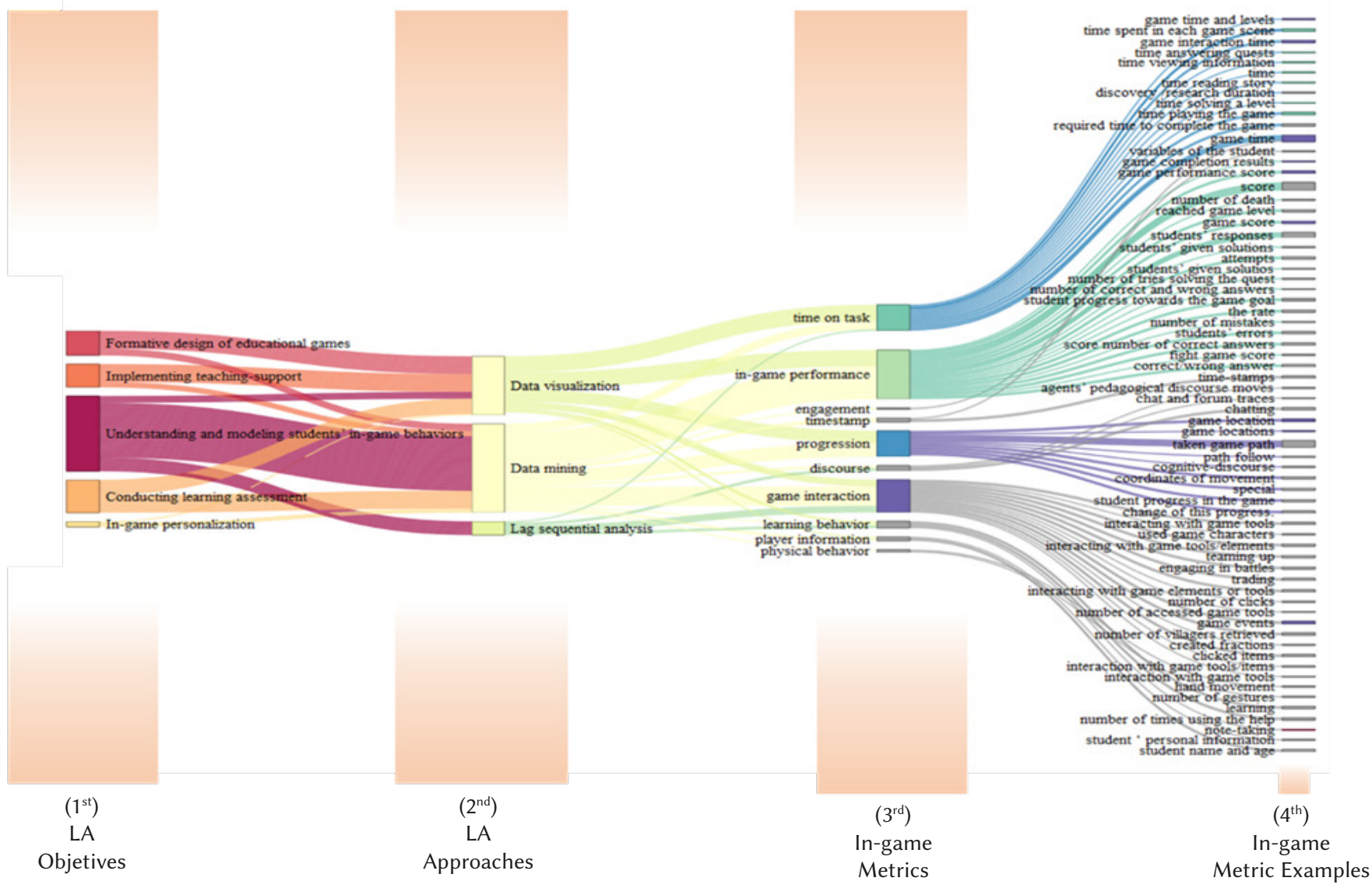

Fig. 3. Sankey diagram of LA objectives, approaches, and in-game metrics.

objectives (identified by RQ 1). Table III shows the major types of ingame metrics with their examples. In general, performance has been the most frequently emphasised target measure in previous studies. Previous studies measured either in-game performance or time on task. Another major type of measure was behavioural (e.g. game interactions, learning behaviours and progression). These metrics provided researchers with analytical information that represented 'enroute' variables of students' behaviours. Lastly, a group of LA metrics - such as discourse, player information and physical behaviour helped researchers understand students' learning behaviours through multiple facets (e.g. discourses and physical behaviours). This type of measure proved beneficial in corroborating the results of both performance and behavioural measures but was shown to be highly dependent on inherited game contexts and data availability.

\section{RQ3. What Types of LA Approaches Were Applied and Used in Educational Games?}

As shown Appendix I, the most used analytics approach was data mining (28 studies), followed by data visualisation (13 studies) and sequential data analytics, or SDA (i.e. lag-sequential analysis, 2 studies). We also confirmed that several studies applied multiple analytics approaches in combination (e.g. both data mining and data visualisation). Data mining aims to discover hidden information and meaningful patterns from massive data, while SDA captures sequential transitions in behaviour events representing learning paths in gameplay [66]. Data visualisation is used to display a variety of visual stimuli, such as pie charts and histograms, to represent data indicating students' learning progression.

Most (60\%) studies applied LA to educational games offline. Specifically, these studies collected the students' traces during the learning process first. They then used external data-mining software, such as Weka, to analyse these traces and extract meaningful information. The rest of the studies $(40 \%)$, on the other hand, incorporated LA within the educational games to provide real-time reports for stakeholders, such as teachers and students. This result is explained by the existing limitation that designing educational games with incorporated analytics systems (i.e. automatic data collection and adaptations) is likely to be more complex and challenging. This is because to provide an adaptive game scenario, game designers and developers need to adapt all the involved game elements (e.g. mechanics, graphics, sounds, etc.) in that scenario to different profiles, which could be time consuming and with high cost. For instance, Denden et al. [33] highlighted that to provide an adaptive educational game based on personality, the game environments that a student can visit, as well the non-player characters to interact with should be personalized.

Fig. 3 is a visual synthesis of our study findings, which mapped the relationship among LA objectives, LA approaches, and the specific in-game metrics from the collected studies. It outlines a visual path indicating how LA objectives, approaches, outcome variables, and in-game metrics are interconnected. Across types of LA objectives in educational games (1st layer, 5 categories), researchers have adopted LA approaches (2nd layer, 3 categories) by drawing on a list of ingame metrics (3rd layer, 10 categories). To evaluate such outcome variables, research has used a collection of in-game metrics (4th layer, 67 examples) in the diagram. The dominant goal of LA in previous studies was to understand and model students' in-game behaviours. Accordingly, the majority of the collected studies have used datamining techniques (2nd layer) to track students' learning as indicated by in-game performance, progression and game interactions (3rd 
layer). Surprisingly, few studies assessed students' outcomes in terms of learning behaviours. Most tended to focus on capturing students' in-game trajectories in relation to game performance. Our study findings suggest that to date, research on LA in educational games has mostly focused on the growth of data-mining techniques to capture, collect and explicate learners' in-game actions.

\section{RQ4. What Are the Challenges in Applying LA in Educational Games?}

After identifying ways of incorporating LA in educational games, this section discusses the reported challenges which can hinder such incorporation. The identified challenges (Appendix I) can be grouped into three categories: (1) techniques; (2) data; and (3) ethics.

\section{Challenges on Techniques}

These concerns are related to the provided infrastructure, including tools for the application of LA in educational games. They are as follows:

- Validations of learning analytics implementations in educational games:

- Previous research also stated the difficulty of incorporating analytic systems in educational games, due to the complexity of designing educational games that contain such systems [48].

- Fine-tuning learning analytics systems across different educational game contexts is necessary to validate the feasible adoptions of the systems (e.g. configuring either universal or contextual sets of variables and tracing rules).

- Lack of game environments to capture students' collaboration:

- Few studies in the sampled literature configured students' collaborations during gameplay [36] [55] [56].

- A lack of collaboration settings in previous studies suggests that there are likely limits on providing social learning experiences through group interactions (e.g. how students collaborate and what type of communication occurs). Further investigation about the application of LA in other game types, namely multiplayer and massively multiplayer, is suggested to capture the effect of social dynamics on game-based and playful learning.

- Reusability of the analytics system: According to existing studies, integrations of LA into educational games appear not to be reusable, because a high degree of variation between educational game developers and educators exists when game metrics are used [15]. Consequently, the cost of designing educational games with analytics systems is high. Therefore, researchers need to focus on developing and providing standardised and scalable LA approaches that can be used across different educational games.

- Big data storage: Educational games encourage learners to be interactive, so that their many traces can be generated and stored. This raises a question of how massive trace data from students can be stored securely [15] [54] [63]. Hence, game developers need to consider ways to store all generated trace data while avoiding losses due to network constraints.

\section{Challenges in Data Collection}

- Identification of important data: Research suggests that the failure to select the important data to be collected from big data storage is likely to limit the application of LA by resulting in the collection of data that cannot be useful later on. Important data should reflect, for instance, students' performance [38] [61]. In this context, Tlili et al. [67] mentioned that data generated during the application of LA should be carefully studied and selected before the collection process begins.
- Identifying relationships between data: Research states that in educational games, it is difficult to see the relationship between traces in order to extract useful information [38]. Therefore, specific metrics should be predefined (depending on the LA goal) and considered during the educational game design. This can facilitate identifying the relationships between metrics that have been previously defined.

\section{Challenges in Ethics}

These challenges relate to the duties and obligations that arise when applying LA in educational games.

- Students' privacy: Existing studies rarely consider how students' privacy is secured when collecting student data in educational games [33]. Pardo and Siemens [68] have suggested that it is necessary to consider appropriate legislation methods for data collection to avoid unintentional violations of students' privacy.

- Transparency of LA: Researchers have highlighted the need to ensure the transparency of collected data, which should be fully open for students. This statement implies that students should be able to retrieve their performance results when they want to during gameplay [33]. This approach can help students feel safe while applying LA and assist in immediately monitoring their learning progress by enabling a 'watch the watcher' process [69].

- Storage time: Researchers were not clearly aware of how long the collected data should be securely stored [33].

- Equity challenge: Only a few studies suggested how LA in educational games could be used to support students with disabilities. The study findings outlined in Appendix I show that $91 \%$ of educational games with LA were aimed at typicaldeveloping students without any disabilities.

\section{Discussion}

\section{A. Academic Implications}

We found that existing LA practices tend to be exploratory (e.g. cluster analysis and sequential analysis). LA implementations in educational games were intended to identify learners' behaviour patterns, as well as their characteristics. Some studies employed cluster analysis to identify either individual or group learning styles and behavioural patterns [32] [38] [42]. The others used SDA to extract and visualise a major set of behaviour sequences representing strategic and engaged gameplay patterns [40] [43]. Such exploratory LA implementations were intended as a means of qualitatively analysing students' gameplay contexts and behaviour patterns through a quantitative lens.

Despite the benefits of exploratory LA studies outlined above, a challenge also exists. Existing exploratory LA practices are post-hoc analyses, which focus on showing what happens during gameplay, and are therefore limited in predicting students' learning challenges in different gameplay paths [39]. In other words, the exploratory post-hoc analyses have limited implications without validating the model performance in context. For example, existing LA practices scarcely address the question of how to provide adaptive supports to assist students in meeting challenges in educational games. Predicting learners' difficulties or challenging experiences is essential to choosing adaptive supports tailored to learners' progressions in gameplay. Hence, once an educational game aims at providing personalised game experiences to students having learning challenges, building a pipeline to connect an adaptive system with such exploratory LA can be suggested in future research. 


\section{Validations of Learning Analytics Measures}

When using LA in educational games, only a few researchers implemented validations of various in-game data with external assessments [11] [61]. In addition to observing learners' trajectories unobtrusively, researchers should also aim to ensure that such game metrics represent target outcome variables as intended. Educational games involve multiple types of game metrics. We can build a bigger picture through multiple learner traces from gameplay. This will enable researchers to implement finer-grained data analyses (e.g., microactions), triangulate the data collected and understand learning processes in detail. For example, synthesising and validating multiple data sources from learners' gameplay is necessary to confirm how such game metrics consistently indicate learners' achievement through gameplay. Especially considering different game design contexts, validating different types of game metrics can be useful in capturing learners' meaningful gameplay reliably.

\section{Lack of Learning Analytics Implementations in Collaborative Educational Games}

We confirm that there is a lack of multiplayer and massively multiplayer games applying LA. This result indicates not only the necessity of designing games that foster collaboration, but also that of implementing LA to understand collaborative experiences. Although the field of LA includes various data-mining and analytics approaches used to understand learners' social dynamics, existing educational games have rarely focused on students' social interactions. Traditional ways of understanding collaboration and peer interactions among learners (e.g. observation, interview, video analysis) are generally time-consuming. LA, however, can distill emerging information much faster, sometimes with greater and unbiased detail, than those methods. It thus raises the question of how future LA practices can be contextualised in educational games that require learners' social interactions.

\section{The Need for Mastery Learning Design in Educational Games}

Despite the increasing growth of data-mining techniques in educational games, there is a dearth of empirical research on how to design and implement an educational game system that supports students' mastery of learning experiences. We have confirmed that previous studies largely focused on understanding and modelling students' in-game behaviours instead of on learning assessment and in-game personalisation. While the former LA objective highlights unobtrusive and externalised data collection related to students' ingame behaviours, the latter influences how likely an educational game is to be designed to enable students' mastery of learning objectives [70]. Specifically, learning assessments and in-game personalisation are means to indicate students' learning progressions and provide automatic and responsive feedback tailored to their learning states. The reported challenges in data collection are also related to the discrepancy between current and potential LA practices. The automation of learning assessments and personalisation requires an educational game to select and define important data features in relation to students' cognitive, behavioural and emotional states. However, limitations in choosing and embedding important data features into educational games and their assessment system still exist [38] [61]. This recalls our study result that few studies on educational games have focused on students' learning behaviours as a major measure in LA. Future educational games should consider ways to reinforce students' mastery of learning experiences.

\section{B. Practical Implications}

In terms of practical implications, we suggest important means through which stakeholders can understand this research field and further work better. First, a collection of game metrics (e.g. interaction with the game tools/elements, followed game path or trajectory, game time, game score, number of wrong/correct answers and chat/forum communication) has been used for different LA applications in educational games. Future educational games can use these and other metrics for different purposes, including to help researchers collect evidence that identifies learners' status in different domains (e.g. cognitive, affective and behavioural) and across various game contexts.

Second, we suggest that educators and practitioners further investigate applications of LA in educational games. Specifically, LA techniques benefit educators by enabling data-driven decisions in communication among all stakeholders. Although educational games have been increasingly used by educators in K-12 settings [5] [42], the integration of LA into educational games is still at the early stage. Such integration should foster communications between teachers and students. Besides, future LA in educational games could take more stakeholders (e.g. parents and administrators) into consideration.

Third, it is important to address the accessibility of educational games with LA. Research has shown the possibility of using LA to help students with disabilities [15] [46] [57]. However, relevant educational policies and acts, as well as inclusive game design standards are scarce. LA can help create a novel way of facilitating access to education by students with disabilities, which will further increase equity and support inclusive learning. In addition, policymakers should emphasise and address the ethical challenges of using LA. Privacy and transparency have been issues not only in educational games with LA, but also in adopting LA into educational systems.

\section{CONClusion, Limitations, AND Future Work}

In this study, we systematically reviewed educational games studies with LA to investigate how LA implementation has evolved. The study findings suggest that: (1) LA in educational games has been used for different purposes, such as student modelling, iterative game design, providing teaching supports and personalisation. (2) Role-playing games and puzzle games in single-player mode are the most common game-setting implementing LA. When LA has been implemented, various game metrics (e.g. interaction with the game tools/elements, followed game path or trajectory, game time, game score) have been used for data input. (3) The most frequently used analytics approaches include data mining and data visualisation. We confirmed that most of the LA approaches are post-hoc and focus on exploring students' in-game trajectories. (4) It is important to address challenges from three perspectives, namely techniques, data and ethics, to ensure the successful integration of LA applications into educational games.

It should be noted that this study has also some limitations that should be acknowledged and further researched. This study included only study findings from empirical journal articles. The narrow scope of data collection in this study limited the number of sampled data and failed to address emerging LA practices expansively. Despite such limitations, this study provides a solid basis for better understanding the ways in which LA in educational games has been contextualised. Future research could investigate ways to integrate LA solutions in educational games by providing a variety of LA examples in educational game contexts. 
APPENDiX I. A List of Selected Literatures As to Learning Analytics in Educational Games

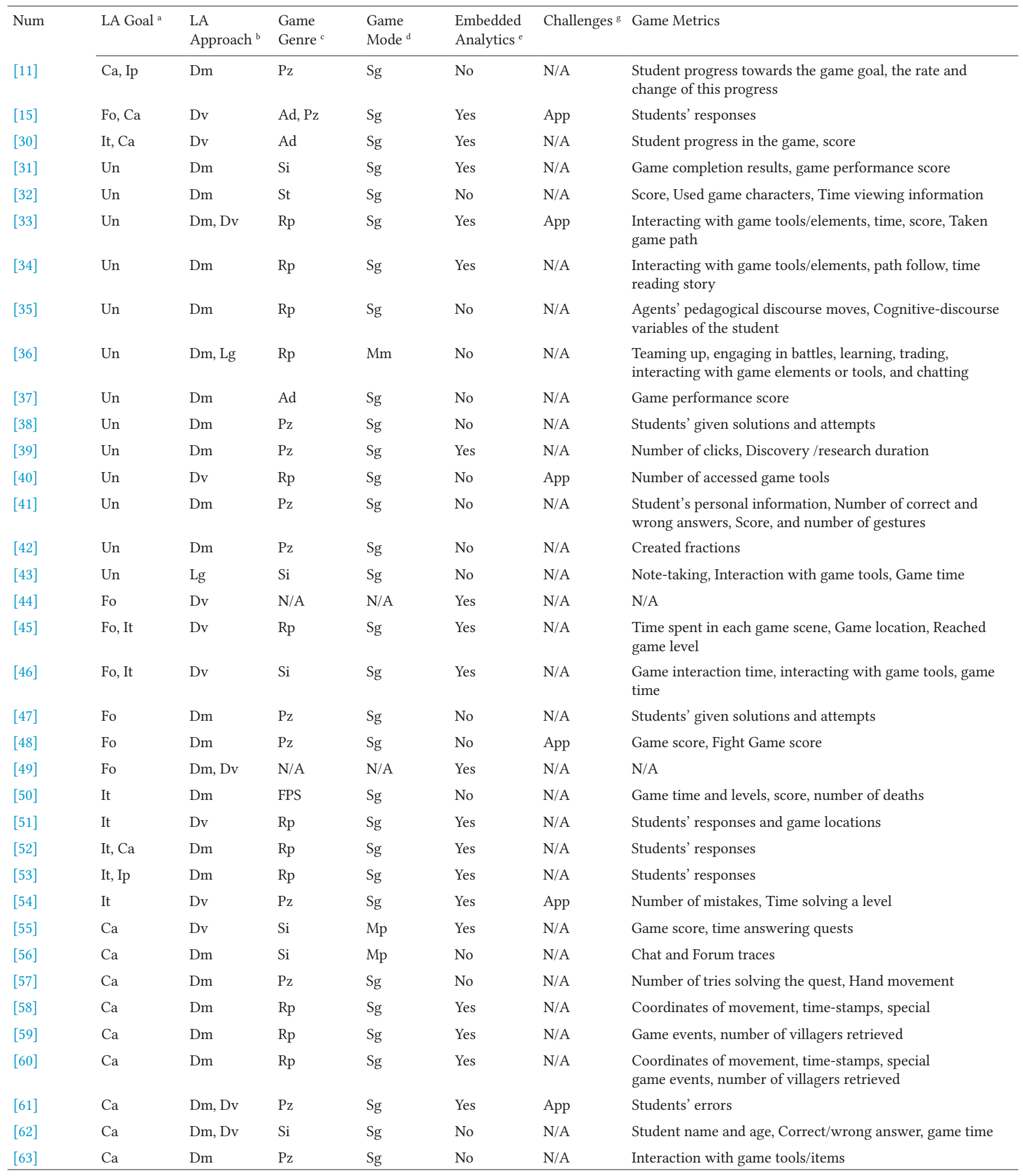

${ }^{\text {a }}$ LA Goal (Un = Understanding and modeling students' in-game behaviors, Fo = Formative design of educational games, It $=$ Implementing teaching support, $\mathrm{Ca}=$ Conducting learning assessment, $\mathrm{Ip}=$ In-game personalization), ${ }^{\mathrm{b}} \mathrm{LA}$ approach $(\mathrm{Dm}=\mathrm{Data}$ mining, $\mathrm{Lg}=\mathrm{Lag}$ sequential analysis, Dv $=$ Data visualization), ${ }^{\mathrm{c}}$ Game Genre $($ Puzzle $=\mathrm{Pz}$, Adventure $=$ Ad, Roleplaying $=\mathrm{Rp}$, Strategy $=$ St, Simulation $=$ Si, First person shooting $=$ FPS, Not applicable $=\mathrm{N} / \mathrm{A}$ ), ${ }^{\mathrm{d}}$ Game Mode (Single player $=\mathrm{Sg}$, Multiplayer $=\mathrm{Mp}$, Massively Multiplayer, $=\mathrm{Mm}$ ), ${ }^{\mathrm{e}}$ Embedded Analytics (Yes or No), ${ }^{\mathrm{f}}$ Game Traces, ${ }^{g}$ Challenges (Applicable $=$ App, Non applicable $=$ N/A). 
REFERENCES

[1] W.-C. Hsu and H.-C. K. Lin, "Impact of applying WebGL technology to develop a web digital game-based learning system for computer programming course in flipped classroom," in International Conference on Educational Innovation through Technology (EITT), Tainan, Taiwan, China, 2016, doi: 10.1109/EITT.2016.20.

[2] F. Ke., "An implementation of design-based learning through creating educational computer games: A case study on mathematics learning during design and computing," Computers \& Education, vol. 73, pp. 26-39, 2014, doi: 10.1016/j.compedu.2013.12.010.

[3] T.-Y. Liu and Y.-L. Chu, "Using ubiquitous games in an English listening and speaking course: Impact on learning outcomes and motivation," Computers \& Education, vol. 55, no. 2, pp. 630-643, 2010, doi: 10.1016/j. compedu.2010.02.023.

[4] S. Suh, S. W. Kim, and N. J. Kim, "Effectiveness of MMORPG-based instruction in elementary English education in Korea," fournal of Computer Assisted Learning, vol. 26, no. 5, pp. 370-378, 2010, doi: 10.1111/j.1365-2729.2010.00353.x.

[5] V. J. Shute, L. Wang, S. Greiff, W. Zhao, and G. Moore, "Measuring problem solving skills via stealth assessment in an engaging video game," Computers in Human Behavior, vol. 63, pp. 106-117, 2016, doi: 10.1016/j. chb.2016.05.047.

[6] D. Burgos, C. Tattersall, and R. Koper, "Re-purposing existing generic games and simulations for e-learning," Computers in Human Behavior, vol. 23, no. 6, pp. 2656-2667, 2006, doi: 10.1016/j.chb.2006.08.002.

[7] P. Moreno-Ger and D. Burgos, "The case for serious games analytics," in Radical Solutions and Learning Analytics: Personalised Learning and Teaching Through Big Data, D. Burgos (Ed.), Singapore: Springer, 2020, pp. 213-227, doi:10.1007/978-981-15-4526-9_13.

[8] D. Burgos, Radical solutions and learning Analytics, Singapore: Springer, 2020.

[9] H. Fournier, R. Kop, and G. Durand, "Challenges to research in MOOCs," fournal of Online Learning and Teaching / MERLOT, vol. 10, no. 1, pp. $1-15,2014$

[10] J. Frommel, K. Rogers, J. Brich, D. Besserer, L. Bradatsch, I. Ortinau, ... and M. Weber, Integrated questionnaires: Maintaining presence in game environments for self-reported data acquisition, in Proceedings of the 2015 Annual Symposium on Computer-Human Interaction in Play, London, United Kingdom, 2015, pp. 359-368.

[11] D. D. Reese, B.G. Tabachnick, and R. E. Kosko, "Video game learning dynamics: Actionable measures of multidimensional learning trajectories," British fournal of Educational Technology, vol. 46, no. 1, pp. 98-122, 2015, doi: 10.1111/bjet.12128

[12] V. J. Shute and M. Ventura, Stealth assessment: Measuring and supporting learning in video games, London, England: The MIT Press, 2013.

[13] B. R. Belland, "The role of construct definition in the creation of formative assessments in game-based learning," in Assessment in gamebased learning, New York, United States: Springer, 2012, pp. 29-42, doi:10.1007/978-1-4614-3546-4_3

[14] V. J. Shute, M. Ventura, M. Bauer, and D. Zapata-Rivera, "Melding the power of serious games and embedded assessment to monitor and foster learning," in Serious games: Mechanisms and effects, New York, United States: Routledge, 2009, pp. 295-321.

[15] Á. Serrano-Laguna, J. Torrente, P. Moreno-Ger, and B. Fernández-Manjón. "Application of LA in educational videogames," Entertainment Computing, vol. 5, no. 4, pp. 313-322. 2014. doi:10.1016/j.entcom.2014.02.003

[16] I. J. Perez-Colado, V. M. Perez-Colado, I. Martínez-Ortiz, M. FreireMoran, and B. Fernández-Manjón, "UAdventure: The eAdventure reboot: Combining the experience of commercial gaming tools and tailored educational tools," in IEEE Global Engineering Education Conference (EDUCON), Athens, Greece, 2017.

[17] A. Tlili, F. Essalmi, M. Jemni, Kinshuk, and N.S. Chen, "A complete validated learning analytics framework: Designing issues from data preparation perspective," International fournal of Information and Communication Technology Education (IfICTE), vol. 14, no. 2, pp. 1-16, 2018, doi: 10.4018/IJICTE.2019070104.

[18] H. Fournier, R. Kop, and H. Sitlia, "The value of learning analytics to networked learning on a personal learning environment," in Proceedings of the 1st International Conference on Learning Analytics and
Knowledge, Banff, Canada, 2011, pp. 104-109, doi:10.1145/2090116.2090131.

[19] S. Powell and S. MacNeill, "Institutional readiness for analytics," fISC CETIS Analytics Series, vol. 1, no. 8, 2012.

[20] D. Gijbels and F. Dochy, "Students' assessment preferences and approaches to learning: can formative assessment make a difference?", Educational Studies, vol. 32, no. 4, pp. 399-409. 2006. doi: 10.1080/03055690600850354.

[21] V.J. Shute and M. Ventura, "Stealth assessment," in The SAGE Encyclopedia of Educational Technology, Thousand Oaks, United States: SAGE, 2015, pp. 675-678, doi: 10.4135/9781483346397.

[22] C.C. van Nimwegen, D. Burgos, H.H. van Oostendorp and H.H. Schijf, "The paradox of the assisted user: guidance can be counterproductive" in Proceedings of the SIGCHI conference on Human Factors in computing systems, Montreal, Canada, 2006, pp.917-926.

[23] C. Alonso-Fernandez, A. Calvo, M. Freire, I. Martinez-Ortiz, and B. Fernandez-Manjon. "Systematizing game learning analytics for serious games" in IEEE Global Engineering Education Conference (EDUCON), Athens, Greece, 2017, pp. 1111-1118.

[24] A. Tlili and M. Chang, "Data analytics approaches in educational games and gamification Systems: Summary, challenges, and future insights," in Data Analytics Approaches in Educational Games and Gamification Systems, Singapore: Springer, 2019, pp. 249-255, doi:10.1007/978-981-329335-9

[25] Z. K. Papamitsiou and A.A. Economides, "Learning analytics and educational data mining in practice: A systematic literature review of empirical evidence," fournal of Educational Technology \& Society, vol. 17, pp. 49-64, 2014.

[26] G. L. Saveski, W. Westera, L. Yuan, P. Hollins, B.F. Manjón, P.M. Ger, and K. Stefanov, "What serious game studios want from ICT research: identifying developers' needs," in International Conference on Games and Learning Alliance, Rome, Italy, 2015, pp. 32-41.

[27] C. Okoli and K. Schabram, "A guide to conducting a systematic literature review of information systems research," Sprouts: Working Papers on Information Systems, vol. 10, no. 26, 2010, doi: 10.2139/ssrn.1954824.

[28] T. M. Connolly, E. A. Boyle, E. MacArthur, T. Hainey, and J. M. Boyle, "A systematic literature review of empirical evidence on computer games and serious games," Computers \& Education, vol. 59, no. 2, pp. 661-686, 2012, doi: 10.1016/j.compedu.2012.03.004.

[29] J. Webster and R. T. Watson, "Analyzing the past to prepare for the future: Writing a literature review," MIS Quarterly, vol. 26, no. 2, pp. 13-23, 2002.

[30] M. Minović, M. Milovanović, U. Šošević, and M. Á. C. González. "Visualisation of student learning model in serious games," Computers in Human Behavior, vol. 47, pp. 98-107, 2015, doi:10.1016/j.chb.2014.09.005.

[31] C. Alonso-Fernández, I. Martínez-Ortiz, R. Caballero, M. Freire, and B. Fernández-Manjón, "Predicting students' knowledge after playing a serious game based on learning analytics data: A case study," fournal of Computer Assisted Learning, vol. 36, no. 3, 2019, doi: 10.1111/jcal.12405.

[32] M. T. Cheng, Y. W. Lin and H. C. She, "Learning through playing virtual Age: Exploring the interactions among student concept learning, gaming performance, in-game behaviors, and the use of in-game characters," Computers \& Education, vol. 86, pp. 18-29, 2015, doi:10.1016/j. compedu.2015.03.007

[33] M. Denden, A. Tlili, F. Essalmi, and M. Jemni, "Implicit modeling of learners' personalities in a game-based learning environment using their gaming behaviors," Smart Learning Environments, vol. 5, no. 1, 2018, doi:10.1186/s40561-018-0078-6

[34] F. Essalmi, A. Tlili, L. J. B. Ayed, and M. Jemni. "Toward modeling the learner's personality using educational games," International fournal of Distance Education Technologies (IFDET), vol. 15, no. 4, pp. 21-38, 2017.

[35] C. M. Forsyth, A. C. Graesser, P. Pavlik Jr, Z. Cai, H. Butler, D. Halpern, and K. Millis. "Operation aries!: Methods, mystery, and mixed models: Discourse features predict affect in a serious game," fournal of Educational Data Mining, vol. 5, no. 1, pp. 147-189, 2013, 10.5281/zenodo.3554615

[36] H. T. Hou, "Exploring the behavioral patterns of learners in an educational massively multiple online role-playing game (MMORPG)," Computers \& Education, vol. 58, no. 4, pp. 1225-1233, 2012, doi: 10.1016/j. compedu.2011.11.015.

[37] R. Israel-Fishelson and A. Hershkovitz, "Persistence in a game-based learning environment: The case of elementary school students learning computational thinking," Journal of Educational Computing Research, vol. 58, no. 5, pp. 891-918, 2019, doi: 10.1177/0735633119887187. 
[38] D. Kerr and G. K. Chung. "Identifying key features of student performance in educational video games and simulations through cluster analysis," fournal of Educational Data Mining, vol. 4, no. 1, pp. 144-182, 2012, doi:10.5281/zenodo.3554647

[39] M. A. Khenissi, F. Essalmi, M. Jemni, T. W. Chang, and N. S. Chen. "Unobtrusive monitoring of learners' interactions with educational games for measuring their working memory capacity," British fournal of Educational Technology, vol. 48, no. 2, pp. 224-245, 2017, doi:10.1111/ bjet. 12445

[40] M. Liu, J. Lee, J. Kang, and S. Liu. "What we can learn from the data: A multiple-case study examining behavior patterns by students with different characteristics in using a serious game," Technology, Knowledge and Learning, vol. 21, no. 1, pp. 33-57, 2016, doi: 10.1007/s10758-015-92637.

[41] E. Lotfi, B. Amine, and B. Mohammed. "Players performances analysis based on educational data mining case of study: Interactive waste sorting serious game," International fournal of Computer Applications, vol. 108, no. 11, pp. 13-19, 2014.

[42] T. Martin, C. Petrick Smith, N. Forsgren, A. Aghababyan, P. Janisiewicz, and S. Baker. "Learning fractions by splitting: Using learning analytics to illuminate the development of mathematical understanding," fournal of the Learning Sciences, vol. 24, no. 4, pp. 593-637, 2015, doi: 0.1080/10508406.2015.1078244.

[43] C. T. Wen, C. J. Chang, M. H. Chang, S. H. F. Chiang, C. C. Liu, F. K. Hwang, and C. C. Tsai. "The learning analytics of model-based learning facilitated by a problem-solving simulation game," Instructional Science, vol. 46, no. 6, pp. 847-867, 2018, doi:10.1007/s11251-018-9461-5.

[44] G. Altanis, M. Boloudakis, S. Retalis, and N. Nikou. "Children with motor impairments play a kinect learning game: First findings from a pilot case in an authentic classroom environment," fournal of Interact Design Architect, vol. 19, pp. 91-104, 2013.

[45] A. Calvo-Morata, D. C. Rotaru, C. Alonso-Fernández, M. Freire, I. Martínez-Ortiz, and B. Fernández-Manjón. "Validation of a cyberbullying serious game using game analytics," IEEE Transactions on Learning Technologies. vol. 13, no. 1, pp. 186-197, 2018.

[46] A. R. Cano, B. Fernández-Manjón, and Á. J. García-Tejedor. "Using game learning analytics for validating the design of a learning game for adults with intellectual disabilities," British fournal of Educational Technology, vol. 49, no. 4, pp. 659-672, 2018.

[47] D. Kerr. "Using data mining results to improve educational video game design," fournal of Educational Data Mining, vol. 7, no. 3, pp. 1-17, 2015.

[48] Á. Serrano-Laguna, B. Manero, M. Freire, and B. Fernández-Manjón. "A methodology for assessing the effectiveness of serious games and for inferring player learning outcomes," Multimedia Tools and Applications, vol. 77, no. 2, pp. 2849-2871, 2018. doi:10.1007/s11042-0174467-6

[49] Y. Chaudy and T. Connolly. "Specification and evaluation of an assessment engine for educational games: Integrating learning analytics and providing an assessment authoring tool," Entertainment Computing, vol. 30, 2019, doi: 10.31686/IJIER.VOL8.ISS3.2220.

[50] M. Callaghan, N, McShane, A. G. Eguíluz, and M. Savin-Baden. "Extending the activity theory based model for serious games design in engineering to integrate analytics," International fournal of Engineering Pedagogy (ifEP), vol. 8, no. 1, pp. 109-126, 10.3991/ijep.v8i1.8087.

[51] Z. H. Chen and S. Y. Lee. "Application-driven educational game to assist young children in learning english vocabulary," fournal of Educational Technology \& Society, vol. 21, no. 1, pp. 70-81, 2018.

[52] K. Kiili and H. Ketamo. "Evaluating cognitive and affective outcomes of a digital game-based math test," IEEE Transactions on Learning Technologies, vol. 11, no. 2, pp. 255-263, 2018.

[53] K. Kiili, K. Moeller, and M. Ninaus, "Evaluating the effectiveness of a game-based rational number training-In-game metrics as learning indicators," Computers \& Education, vol. 120, pp. 13-28, 2018, doi: 10.1016/j.compedu.2018.01.012.

[54] D. Rodríguez-Cerezo, A. Sarasa-Cabezuelo, M. Gómez-Albarrán, and J. L. Sierra, "Serious games in tertiary education: A case study concerning the comprehension of basic concepts in computer language implementation courses," Computers in Human Behavior, vol. 31, pp. 558-570, 2014, doi: 10.1016/j.chb.2013.06.009.

[55] A. Capatina, G. Bleoju, E. Rancati, and E. Hoareau, "Tracking precursors of learning analytics over serious game team performance ranking," Behaviour \& Information Technology, vol. 37, no. 10-11, pp. 1008-1020, 2018, doi:10.1080/0144929X.2018.1474949.

[56] A. B. Hernández-Lara, A. Perera-Lluna, and E. Serradell-López. "Applying learning analytics to students' interaction in business simulation games: The usefulness of learning analytics to know what students really learn," Computers in Human Behavior. vol. 92, pp. 600-612. 2018, doi: 10.1016/j. chb.2018.03.001.

[57] M. Kourakli, I. Altanis, S. Retalis, M. Boloudakis, D. Zbainos, and K. Antonopoulou. "Towards the improvement of the cognitive, motoric, and academic skills of students with special educational needs using Kinect learning games," International fournal of Child-Computer Interaction, vol. 11, pp. 28-39, 2017, doi:10.1016/j.ijcci.2016.10.009.

[58] C. S. Loh and Y. Sheng. "Maximum similarity index (MSI): A metric to differentiate the performance of novices vs. multiple-experts in serious games," Computers in Human Behavior, vol. 39, pp. 322-330, 2014, doi: 10.1016/j.chb.2014.07.022.

[59] C. S. Loh and Y. Sheng. "Measuring the (dis-) similarity between expert and novice behaviors as serious games analytics," Education and Information Technologies, vol. 20, no. 1, pp. 5-19, 2015, doi: 10.1007/ s10639-013-9263-y.

[60] C. S. Loh, Y. Sheng, and I. H. Li. "Predicting expert-novice performance as serious games analytics with objective-oriented and navigational action sequences," Computers in Human Behavior, vol. 49, pp. 147-155, 2015. doi: 10.1016/j.chb.2015.02.053.

[61] E. Rowe, J. Asbell-Clarke, R. S. Baker, M. Eagle, A. G. Hicks, T. M. Barnes, and T. Edwards. "Assessing implicit science learning in digital games," Computers in Human Behavior, vol. 76, pp. 617-630, 2017, doi: 10.1016/j. chb.2017.03.043.

[62] A. Slimani, F. Elouaai, L. Elaachak, O. B. Yedri, M. Bouhorma, and M. Sbert. "Learning analytics through serious games: Data mining algorithms for performance measurement and improvement purpose," International fournal of Emerging Technologies in Learning (ifET), vol. 13, no. 1, pp. 46-64, 2018.

[63] E. L. Snow, L. K. Allen, M. E. Jacovina, and D. S. McNamara. "Does agency matter?: Exploring the impact of controlled behaviors within a gamebased environment," Computers \& Education, vol. 82, pp. 378-392, 2015. doi: 10.1016/j.compedu.2014.12.011.

[64] K. Becker, "How are games educational? Learning theories embodied in games," in DiGRA: Changing Views - Worlds in Play. Vancouver, Canada, 2005.

[65] E. Z. F., Liu, and C. H. Lin. "Developing evaluative indicators for educational computer games," British fournal of Educational Technology, vol. 40, no. 1, pp. 174-178, 2009, doi:10.1111/j.1467-8535.2008.00852.x.

[66] J. Moon and Z. Liu. "Rich Representations for Analyzing Learning Trajectories: Systematic Review on Sequential Data Analytics in GameBased Learning Research," in Data Analytics Approaches in Educational Games and Gamification Systems, Tlili A., Chang M. (eds), Singapore: Springer, 2019.

[67] A. Tlili, F. Essalmi, and M. Jemni, "An educational game for teaching computer architecture: Evaluation using learing analytics," in 5th IEEE International Conference on Information \& Communication Technology and Accessibility (ICTA), Marrakech, Morocco, 2016, pp. 1-6.

[68] A. Pardo and G. Siemens, "Ethical and privacy principles for learning analytics," British fournal of Educational Technology, vol. 45, no. 3, pp. 438-450, 2014, doi: 10.1111/bjet.12152.

[69] S. Welsh and S. McKinney, "Clearing the Fog: A learning Analytics Code of Practice," in Proceedings of the Australasian Society for Computers in Learning in Tertiary Education, T. Reiners, B.R. von Konsky, D. Gibson, V. Chang, L. Irving, \& K. Clarke (Eds.), Perth, Australia. 2015.

[70] S. Erhel and E. Jamet. "Digital game-based learning: Impact of instructions and feedback on motivation and learning effectiveness," Computers \& Education, vol. 67, pp. 156-167, 2013, doi: 10.1016/j.compedu.2013.02.019. 


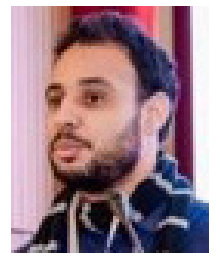

\section{Ahmed Tlili}

Ahmed Tlili is the Co-Director of the OER Lab at the Smart Learning Institute of Beijing Normal University (SLIBNU), China. He serves as the Associate Editor of the IEEE Bulletin of the Technical Committee on Learning Technology, and the Journal of e-Learning and Knowledge Society. He is also a Visiting Professor at UNIR-iTED, Spain, and an expert at the Arab League Educational, Cultural and Scientific Organization (ALECSO). Dr. Tlili has been awarded the IEEE TCLT Early Career Researcher Award in Learning Technologies for 2020. He has edited several special issues in indexed journals. He has also published several books, as well as academic papers in international referred journals and conferences. He is serving as a local organizing and program committee member in various international conferences, and as a reviewer in several refereed journals. Dr. Tlili is the Co-Chair of IEEE special interest group on "Artificial Intelligence and Smart Learning Environments" and APSCE's Special Interest Group on "Educational Gamification and Game-based Learning (EGG)". His research interests include, open education, game-based learning, educational psychology and artificial intelligence.

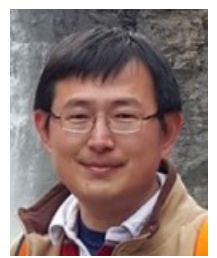

Maiga Chang

Maiga Chang is currently a Full Professor with the School of Computing Information and Systems, Athabasca University, Canada. He has given more than 105 talks and lectures in different conferences, universities, and events. He has participated in more than 310 international conferences and workshops as a Program Committee Member. He has (co-)authored more than 225 edited books, special issues, book chapters, journal and international conference papers. He is the Editor-in-Chief of the Educational Technology and Society, the Bulletin of Technical Committee on Learning Technology, and the International Journal of Distance Education Technologies. He was a Section Editor of the Education and Science, an Associate Editor of Transactions on Edutainment (Springer). $\mathrm{He}$ is an Advisory Board Member of the Journal of Computers and Applied Science Education. He is also the Chair of the IEEE Technical Committee of Learning Technology (IEEE TCLT), an Executive Committee Member of the Asia-Pacific Society for Computers in Education (APSCE), the Global Chinese Society for Computing in Education (GCSCE), and the Chinese Society for Inquiry Learning (CSIL). He is a Secretary and a Treasurer of the International Association of Smart Learning Environments (IASLE).

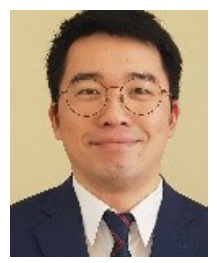

\section{Jewoong Moon}

Jewoong Moon is a Ph.D. candidate at the Department of Educational Psychology and Learning Systems at Florida State University, United States. His research interests include digital game-based learning, immersive learning environment design for neurodiverse learners, learning analytics \& educational data mining, and adaptive learning system design. He is currently investigating multimodal data fusion implementation to develop predictive models as stealth assessment for adaptive and immersive learning environments.

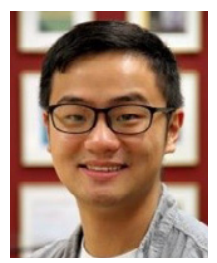

Zhichun "Lukas" Liu

Dr. Zhichun "Lukas" Liu is a postdoctoral fellow at Kaput Center of Research and Innovation in STEM Education, University of Massachusetts Dartmouth. His current work aims at using game-based learning to promote the development and learning transfer of computational thinking among K-12 students and teachers. His research interests also include using quantitative analytics methods to understand learners' behavior, competence, discourse, and interactions.

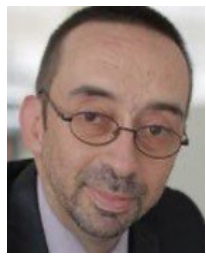

Daniel Burgos

Daniel Burgos received a postgraduate in artificial intelligence \& machine learning from MIT, and the Ph.D. degree in communication, the Dr.Ing. degree in computer science, the Ph.D. degree in education, the Ph.D. degree in anthropology, and the D.B.A. degree in business administration. He works currently as a Full Professor of technologies for education \& communication and ViceRector for International Research, UNESCO Chair of eLearning, and ICDE Chair of open educational resources at Universidad Internacional de La Rioja. $\mathrm{He}$ is also the Director of the Research Institute for Innovation \& Technology in Education (UNIR iTED). Further, he is a Professor with An-Najah National University, Palestine, an Adjunct Professor with the Universidad Nacional de Colombia (UNAL), Colombia, an Extraordinary Professor with North-West University, South Africa, a Visiting Professor with Coventry University, U.K., and the Universidad de las Fuerzas Armadas (ESPE), Ecuador. He has published over 150 scientific articles, 20 books, and 15 special issues on indexed journals. He has developed +55 European and Worldwide Research and Development projects. His research interests include adaptive, personalised and informal eLearning, learning analytics, open education and open science, eGames, and eLearning specifications.

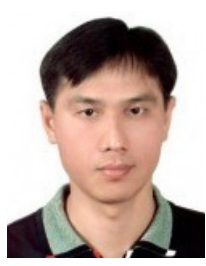

Nian-Shing Chen

Nian-Shing Chen is currently Chair Professor in the Department of Applied Foreign Languages at the National Yunlin University of Science and Technology, Taiwan. He has published over 400 academic papers in the international referred journals, conferences and book chapters. One of his papers published in Innovations in Education and Teaching International was awarded as the top cited article in 2010. He is the author of three books with one textbook entitled "e-Learning Theory \& Practice". He has received the national outstanding research awards for three times from the National Science Council in 2008, 2011-2013 and the Ministry of Science and Technology in 2015-2017. His current research interests include assessing e-Learning course performance; online synchronous teaching \& learning; mobile \& ubiquitous learning; gesture-based learning and educational robotics.

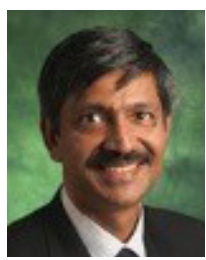

Kinshuk

Kinshuk is currently a Professor of Computer Science and the Dean of the College of Information at the University of North Texas, USA. He received the Ph.D degree in computer science from the University of De Montfort, England, in 1996. He held the NSERC/CNRL/Xerox/McGraw Hill Research Chair for Adaptivity and Personalization in Informatics, funded by the Federal government of Canada, Provincial government of Alberta, and by national and international industries. Area of his research interests include learning analytics; learning technologies; mobile, ubiquitous and location aware learning systems; cognitive profiling; and interactive technologies. 